tion of a relatively small dose on alternate days it would appear that the course of his disease has been reduced from one causing major to one causing minimal incapacity. How long it will be possible to continue replacement therapy in this way remains to be seen, but it may offer a useful means of tiding severe haemophiliacs over serious exacerbations of their disease. The risk of homologous serum jaundice would appear to be appreciable, but our patient had had so many previous administrations of plasma that it was thought likely that he had developed immunity. An additional risk of the production of antibody to antihaemophilic globulin or other globulins must be borne in mind. Those patients who possess trace amounts of antihaemophilic globulin and who presumably do not suffer from a complete gene deletion would seem unlikely to develop antihaemophilic globulin antibodies, and so far no $\gamma$-globulin antibodies have been detected in our patient. If prolonged treatment

\section{Delayed Perforation of Large Bowel Due to Unusual Ingested Foreign Body}

\section{Brit. med.F., 1967, 4, 532}

A blunt ingested foreign body usually does not give rise to any trouble once it has negotiated the ileocaecal junction. In the present case, obstruction and later perforation of the colon resulted from massive impaction of cloth fabric.

\section{Case Report}

A 29-year-old woman was admitted as an emergency case because of a five-day history of lower abdominal colicky pain, vomiting, and constipation. Early laparotomy seemed indicated because of a firm tender mass in the pouch of Douglas which was thought to be a twisted ovarian cyst.

Operative Findings.- Some clear serous fluid was found in the peritoneal cavity, but the ovaries were normal. The whole of the large bowel was loaded down to almost the rectosigmoid junction. The rectum and the distal few inches of the sigmoid colon were empty and appeared normal to inspection and palpation. The distension was maximal in the pelvic colon, which was congested, thickened, and oedematous. It was angry-looking and the appearance was not unlike that of Crohn's disease. However, the mesentery and its lymph nodes were not involved. There was an area of necrosis measuring about $3 \mathrm{~mm}$. in diameter in the wall of the pelvic colon, situated between the mesenteric border and the anterior taenia coli. This was of paper-like thickness, was light green in colour, and was covered with purulent exudate. The adjacent appendices epiploicae were also involved by this acute inflammatory process. There was no evidence of any diverticulosis or diverticu-

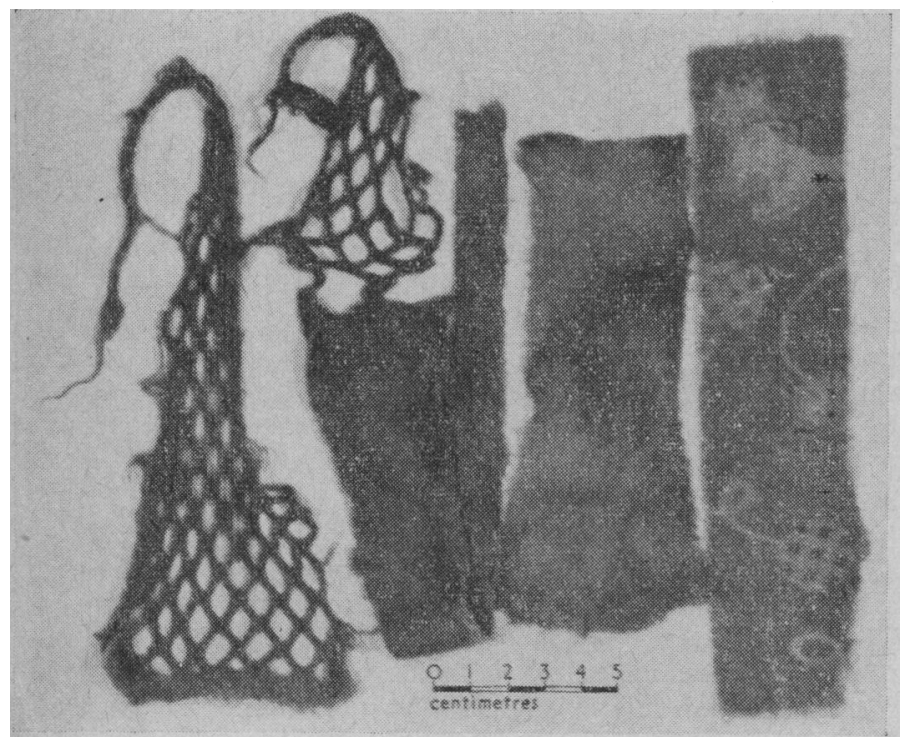

Photograph showing some of the ingested material.

of haemophilia in this way is practicable, more adequate provision of cryoprecipitate on a national scale will be required.

A. BeLlinghaM, M.B., B.S., M.R.C.P.

D. FletCHER, M.B., D.PHYS.MED.

E. O'G. KIRWAN, M.B., B.CHIR., F.R.C.S.

T. A. J. PRANKERD, M.D., F.R.C.P.

University College Hospital, London W.C.1.

T. CleghoRn, M.D., B.SC., F.C.PATH.

North London Blood Transfusion Centre, Edgware, Middlesex.

\title{
REPERENCRS
}

Bennett, E., Dormandy, K. M., Churchill, W. G. L., Coward, A. R., Smith, M., and Cleghorn, T. E. (1967). Brit. med. $7 ., 2,88$.

Brown, D. L., Hardisty, R. M., Kosoy, M. H., and Bracken, C. (1967). Ibid., 2, 79

Hardisty, R. M., and Ingram, G. I. C. (1965). Bleeding Disorders. Oxford.

Pool, J. G., and Shannon, A. E. (1965). New Engl. Y. Med., 273, 1443.

litis. As perforation seemed imminent, the loop of pelvic colon was exteriorized after milking down its contents.

The diagnosis of this strange lesion was made on the fourth postoperative day, when the milked-down contents were passed per rectum. These consisted of several portions of cloth fabric, mostly derived from vests, stocking, and pyjamas (see illustration). On the ninth postoperative day the exteriorized pelvic colon was opened as the patient had become acutely obstructed. After this many yards of fabric, mainly in lengths of about $15 \mathrm{~cm}$., were removed from the colon.

On the thirteenth postoperative day she developed faecal peritonitis after perforation of the descending colon due to impacted fabric, and a transverse colostomy was performed. Her convalescence was stormy and prolonged, but eventually she left hospital after closure of the two colostomies.

\section{COMMENT}

Only two cases of perforation of the large bowel due to blunt foreign bodies have been reported in the medical literature. In the case reported by Williamson (1952) it was the result of a gall-stone impaction, while in Goatcher's (1953) case the cause was similar to the present one.

Ward-McQuaid (1950) studied the various types of ingested foodstuffs which could cause intestinal obstruction but rarely perforation and found that the terminal ileum was the commonest site of impaction.

The above case becomes interesting from various points of view: (1) On routine examination of the patient one would not have thought of any mental retardation. She was happily married and had two children. However, she was later seen by a psychiatrist, who found her to be mentally deficient. (2) The pathology of impending perforation has not been described previously ; as in Goatcher's case, it was missed by prolonging the conservative treatment. The appearance can easily be confused with Crohn's disease, particularly if the impaction should take place in the terminal ileum. (3) Though the patient presented as a case of intestinal obstruction, a delayed perforation and faecal peritonitis could not be avoided as in Goatcher's case. To guard against such a complication should such a case be discovered at laparotomy it is advisable to perform a colostomy and milk out all the impacted material.

I wish to thank Mr. J. M. Moore for his guidance in the management of this case and useful suggestions in the preparation of the paper.

\section{Ballochmyle Hospital, Mauchline, Ayrshire.}

D. D. GAUR,* M.S., F.R.C.S., Ex-Registrar in General Surgery.

- Now Consultant Surgeon, Bombay Hospital, 12 Marine Lines, Bombay 1.
REFERENCES

Goatcher, P. (1953). Brit. F. Surg., 41, 286. Ward-McQuaid, N. (1950). Brit. med. \%., 1, 1106. Williamson, J. C. F. Lloyd (1952). Brit. Э. Surg., 39, 339. 